\title{
SEDIMENT TRANSPORT AT RIVER CONTRACTIONS
}

\author{
GIUSEPPE OLIVETO \\ School of Engineering, University of Basilicata, Italy
}

\begin{abstract}
River contractions might occur because of either natural controls or hydraulic works. This paper aims to provide new insights on the temporal evolution of the morphological patterns at river contractions based on experiments at laboratory scale. Laboratory tests were performed in a $20 \mathrm{~m}$ long straight channel having a rectangular cross section, $1.0 \mathrm{~m}$ wide and $1.0 \mathrm{~m}$ deep. The erodible bed reach was made by almost uniform sediment consisting of either rough sand or medium gravel. The contraction model was $0.5,1.0,2.0$, or $3.0 \mathrm{~m}$ long. Three contraction ratios $\beta=b / B=0.9,0.8$, and 0.7 were considered, with $b$ width of the contracted reach and $B$ width of the approach channel. The experiments were performed in clear-water scour regime and steady flow conditions. Typically, they were of long duration (up to 15 days) to achieve conditions of dynamic equilibrium, but runs of short duration were also carried out to acquire suitable experimental data at the earlier stages of the bed forms development. Compared to previous studies by the author on the same topic, new results are provided on bed morphology characteristics, also considering literature data, and predictive models on the timedependent development of the bed degradation in and downstream of the contracted area.
\end{abstract}

Keywords: river contraction, scouring, sediment transport.

\section{INTRODUCTION}

In a paper of 1934, Straub [1] emphasized how river contractions typically occur when structures are built for narrowing the river so as to obtain a greater navigable bed. Gill [2] observes that the river channel within the parallel guide banks, built on diversion works such as weirs and barrages, is a practical example of rectangular long contraction. By way of example, he shows that at the site of the Mailsi Siphon, Pakistan, the natural width of the Sutlej river is reduced from $12 \mathrm{~km}$ to merely $432.0 \mathrm{~m}$. In more general terms, Dey and Raikar [3] highlight that contractions of river width in building bridges, barrages, weirs, and crossdrainage works are common examples of channel contractions. Moreover, partial closure required for the maintenance of channel riverbanks, such as construction of cofferdam and end-dump channel constriction, is the other type of channel contraction.

The flow velocity in a channel contraction increases due to the reduction of the flow area. The bed shear stresses therefore increase, and hence scour processes may occur. Several predictive models have been proposed for estimating the maximum scour depth at channel contractions. A large part of these models are based on the DuBoys' transport formula and Manning's equation (e.g. Gill [2], Laursen [4], Komura [5], Lim [6], Lim and Cheng [7]). In 2005 Dey and Raikar [3] published a paper on long contractions with uniform and nonuniform sediments by making available the experimental data for 131 runs under clear-water scour. Later, Dey and Raikar [8] proposed an analytical model for the computation of livebed scour depth in long contractions, based on the energy and continuity equations. The scour depths computed from the model were found in satisfactory agreement with experimental data. Previously proposed equations for estimation of the equilibrium scour depth were compared with experimental data and the comparison revealed that the equation proposed by Lim [6] was the best predictor among those compared. Brandimarte et al. [9] developed a probabilistic framework to calculate the probability density function and exceedance probability of the estimated contraction scour depth over the life of a bridge. 
Compared to laboratory experimental studies, field investigations are still limited. As examples, Benedict [10] measured clear-water contraction scour in the South Carolina Piedmont; Mueller and Wagner [11] conducted an analysis of the available field data for contraction scour. They compared field data with estimates from the formulas of Straub, Laursen, and Komura. The results revealed overprediction in most cases, but instances of underprediction also occurred. Detailed real-time measurements of flow velocities and bed elevations for a flood in 1997 on the Pomme de Terre River in Minnesota are also provided. Hong and Abid [12] carried out laboratory experiments using a 1:45 scale hydraulic model of the Ocmulgee River Bridge at Macon, Georgia including upstream and downstream river reaches and bridge structure. The experimental studies elucidated the interaction between local pier scour and contraction scour. Comparisons are made between scour measurements in the laboratory and in the field.

Nevertheless, current literature data are still insufficient to assess reliable equations especially when the effect of the time is included. More important, most of the literature papers consider conditions of dynamic equilibrium, and hence concentrate on the maximum scour depth, overlooking the analysis of the channel bed morphology in its entirety, both in and outside the contracted zone. Based on experiments at laboratory scale and compared to previous papers by the author on the same topic (Oliveto and Marino [13]-[15]), new results are given in terms of empirical equations on the peculiar bed morphology characteristics also considering literature data, and predictive models on the temporal development of the bed degradation in and downstream of the contracted area.

\section{EXPERIMENTS}

Experiments were made at the Hydraulic Engineering Laboratory, University of Basilicata, Italy, in a $1 \mathrm{~m}$ wide and $20 \mathrm{~m}$ long rectangular straight channel. In total 22 runs were performed.

The mobile bed was from 10 up to $16 \mathrm{~m}$ long depending on the contraction model length. Two bed sediments were tested either a nearly uniform (in size) sand with median grain size $d_{50}=1.7 \mathrm{~mm}$, sediment gradation $\sigma=\left(d_{84} / d_{16}\right)=1.5$, and dimensionless grain size $D^{*}=\left(g^{\prime} / v^{2}\right)^{1 / 3} d_{50}=43$ or a nearly uniform (in size) gravel with $d_{50}=9.0 \mathrm{~mm}, \sigma=1.5$, and $D^{*}=228 . \quad v$ is the kinematic viscosity of water and $g^{\prime}$ is the modified gravitational acceleration equal to $g\left(\rho_{s}-\rho\right) / \rho$, with $\rho$ mass density of water, $\rho_{s}$ mass density of sediment, and $g$ gravitational acceleration. The sand bed was used to simulate transition conditions at the interface sediment-water while the gravel bed hydraulically rough conditions, according to the Shields' diagram. The approaching mobile bed upstream of the contraction model was at least $5 \mathrm{~m}$ long to facilitate the development of fully turbulent flow. Whereas, the mobile bed downstream of the contraction model was at least $3 \mathrm{~m}$ long for allowing an undisturbed evolution of the bed morphology.

The contraction model was formed by means of three parts. The middle one was straightlined of length $l$ either $0.5,1.0,2.0$, or $3.0 \mathrm{~m}$; the upstream inlet transition and the downstream outlet transition were identical in shape and nearly streamlined to reduce energy losses and local scour effects. Three contraction ratios $\beta=b / B$ were tested either $0.9,0.8$, or 0.7 , with $b$ the width of the contraction model in its middle part and $B$ the width of the uncontracted channel. Overall, the ratio of $b$, and hence of $B$, to the approach flow depth $h_{o}$ was kept $>4$ to minimize sidewall effects [16].

Further details on the experimental work, main test conditions and results for each run included, are provided in Oliveto and Marino [13]-[15]. With reference to the run 21 characterised by sandy movable bed, contraction ratio $\beta=0.70$, contraction length 
$l=3.00 \mathrm{~m}$, discharge $Q=0.040 \mathrm{~m}^{3} / \mathrm{s}$, and approach flow depth $h_{o}=0.100 \mathrm{~m}$, Fig. 1 shows the free surface features and the bed morphology at the end of the run just after the channel was drained.

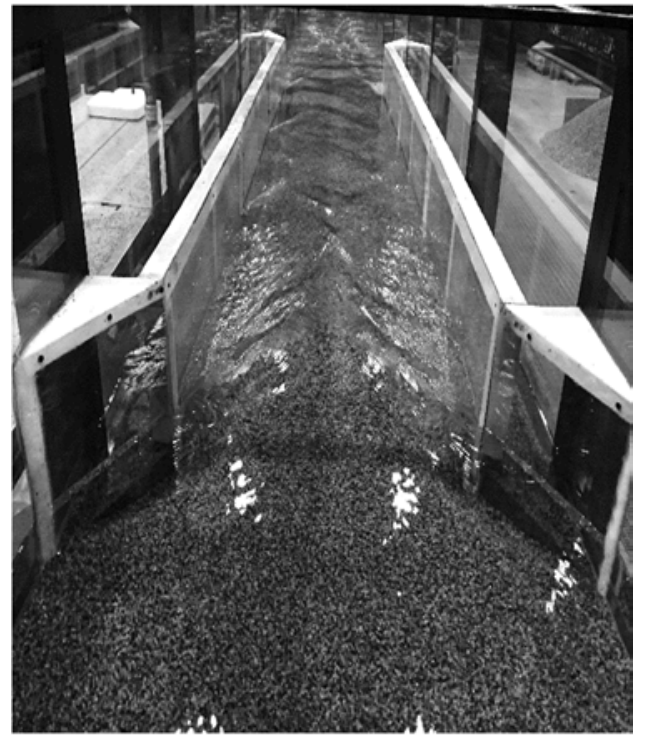

(a)

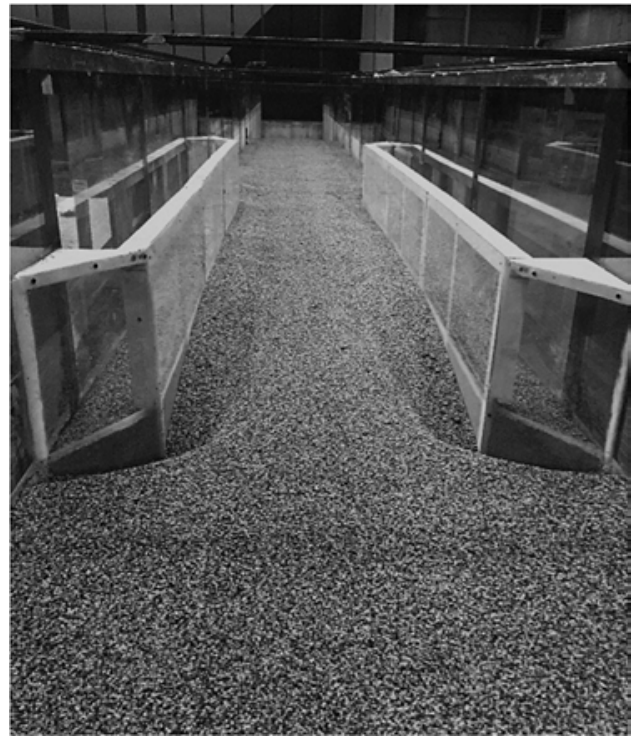

(b)

Figure 1: $\quad$ Run 21 with contraction ratio $\beta=0.70$, contraction length $l=3.00 \mathrm{~m}$, discharge $Q=0.040 \mathrm{~m}^{3} / \mathrm{s}$, and approach flow depth $h_{o}=0.100 \mathrm{~m}$. (a) Free surface; and (b) Bed morphology at the end of the run.

\section{ANALYSIS OF DATA AND RESULTS}

In sediment transport processes at channel contractions, the maximum scour depth $z^{*}$ at a given time $t$ can be expressed in functional form as:

$$
z^{*}=f\left(V_{o}, h_{o}, v, \rho, \rho_{s}, d_{50}, \sigma, B, b, l, g, t\right),
$$

in which $V_{o}$ is the approach flow velocity, $h_{o}$ is the approach flow depth, $v$ is the kinematic viscosity, $\rho$ is the mass density of the water, $\rho_{s}$ is the mass density of the sediment, and $g$ is the gravitational acceleration.

In two-phase flow phenomena with sediment-water interaction, it is appropriate to group the independent variables $g, \rho$, and $\rho_{s}$ into $g^{\prime}=g\left(\rho_{s}-\rho\right) / \rho$ as done by [3], [17]. Also, the contraction ratio $\beta=b / B$ can be introduced in order to account for the combined effect of $b$ and $B$. In addition, the influence of $v$ in turbulent flow over a rough bed can be considered negligible [3]. Hence, the functional eqn (1) simplifies as

$$
z^{*}=f\left(V_{o}, h_{o}, d_{50}, \sigma, \beta, l, g^{\prime}, t\right) .
$$

Applying the Buckingham $\pi$ theorem with repeating variables $h_{o}$ and $V_{o}$, and rearranging the dimensionless parameters in a similar way as in [17], yields

$$
Z^{*}=\frac{z^{*}}{h_{o}}=\left(F_{d}, \frac{h_{o}}{d_{50}}, \sigma, \beta, \frac{l}{h_{o}}, T\right),
$$


with $F_{d}$ the densimetric Froude number defined as $V_{o} /\left(g^{\prime} d_{50}\right)^{1 / 2}$ and $T$ a dimensionless time defined as $\left(g^{\prime} d_{50}\right)^{1 / 2} t / h_{o}$. The same functional relationship applies to $L^{*}=l^{*} / h_{o}$, in which $l^{*}$ is the scour hole length.

The experimental data collected at the University of Basilicata and those by Dey and Raikar [3] were used for regression analysis, which yields the following equation in the case of $z^{*}$

$$
Z^{*}=0.025\left(\frac{h_{o}}{d_{50}}\right)^{-0.16}\left(1+\frac{l}{h_{o}}\right)^{0.64}\left(\frac{1-\beta}{\beta}\right)^{1.02} F_{d}^{1.65} T^{0.09},
$$

with coefficient of determination $r^{2}=0.84$ between observed and computed values of $z^{*}$ (Fig. 2(a)). Eqn (4) is consistent with the condition that $Z^{*}$ is equal to zero for $\beta=1$ and tends to infinity when $\beta$ goes to zero. It is also consistent with the condition that $Z^{*}$ should not necessarily be zero when $l=0$. The sediment gradation $\sigma$ was not considered in this analysis because all the bed sediments used in the experiments were nearly uniform.

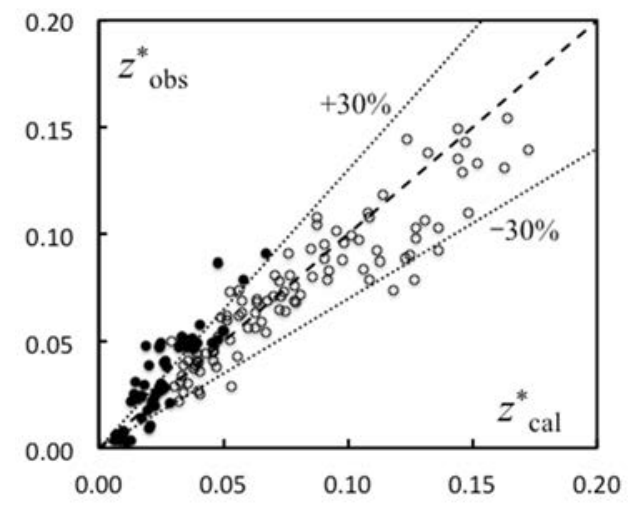

(a)

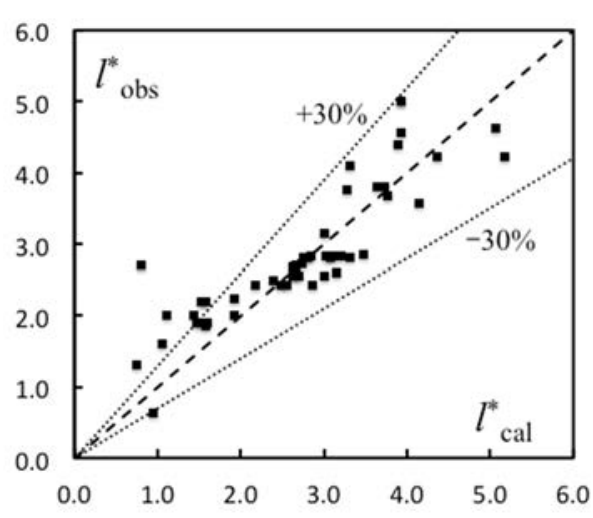

(b)

Figure 2: (a) Comparison between observed (subscript "obs") and calculated (subscript "cal") values of $z^{*}$ for the data collected at the University of Basilicata (black symbols) and the data by Dey and Raikar [3] (white symbols). The values of $z^{*}$ are in meters; (b) Comparison between observed and calculated values of $l^{*}$ for the data collected at the University of Basilicata. The values of $l^{*}$ are in meters.

Fig. 2(a) shows that the data points are reasonably well close to the line of perfect agreement with deviations generally within $\pm 30 \%$. However, the data collected at the University of Basilicata appear somewhat underestimated. This discrepancy between the two datasets may be explained by the fact that in the case of the data by Dey and Raikar [3] the exact duration of each run is unknown and here it was assumed always equal to 24 hours according to the authors' statement that the experiments were run for a period more than 24 hours. Moreover, the experiments by Dey and Raikar [3] were carried out in a somewhat narrow channel $(0.6 \mathrm{~m}$ wide) which could lead to some scale effects. A slightly more conservative equation for $Z^{*}$ could therefore be

$$
Z^{*}=0.025\left(\frac{h_{o}}{d_{50}}\right)^{-0.16}\left(1+\frac{l}{h_{o}}\right)^{0.64}\left(\frac{1-\beta}{\beta}\right)^{1.02} F_{d}^{1.65} T^{0.12} .
$$


There are not systematic literature data in the case of $l^{*}$, then the experimental data collected at University of Basilicata only were considered for regression analysis, which yields the following equation

$$
L^{*}=1.244\left(\frac{h_{o}}{d_{50}}\right)^{-0.40}\left(1+\frac{l}{h_{o}}\right)^{0.80}\left(\frac{1-\beta}{\beta}\right)^{-0.19} F_{d}^{1.87} T^{0.08},
$$

with coefficient of determination $\mathrm{r}^{2}=0.69$ between observed and calculated values of $l^{*}$ (Fig. 2(b)). Interestingly, $L^{*}$ was found practically independent of the contraction ratio $\beta$ while dependent on $l^{*} / h_{o}$ significantly, as expected.

Moreover, the observed scour hole profiles along the channel centreline were analysed. After several attempts, a moderate data scattering was achieved by normalizing the scour depth along the channel centreline with $z^{*}$ and its location from the upstream end of the contraction model with $l^{*}$. The following tentative equation was found

$$
Z=2.92 X^{4}-11.85 X^{3}+15.36 X^{2}-6.11 X-0.27,
$$

where, with reference to the generic scour depth, $z$, along the channel centreline, $Z$ is the ratio of $z$ to the maximum scour depth $z^{*}$ and $X$ is the ratio of the distance of $z$ from the upstream end of the contraction model to $l^{*}$. Eqn (7) needs a more extensive validation and then its coefficients cannot be considered as final, however it is interesting to observe how it predicts the scour hole and the sediment mound along the channel centreline confidently. To this purpose, Fig. 3 shows the comparison between the observed data and eqn (7) for runs 20, 21 , and 22. In applying eqn (7), $z^{*}$ was estimated from eqn (5) and $l^{*}$ from eqn (6). Runs 20 and 21 were characterised by $Q=0.040 \mathrm{~m}^{3} / \mathrm{s}, h_{o}=0.10 \mathrm{~m}, \beta=0.70$, and $l=3.00 \mathrm{~m}$ and run 22 by $Q=0.060 \mathrm{~m}^{3} / \mathrm{s}, h_{o}=0.15 \mathrm{~m}, \beta=0.70$, and $l=3.00 \mathrm{~m}$. It should also be noted that the bed degradation extends (downstream) beyond the contracted reach up to a distance of about $1.5 \cdot l$ in case of runs 20 and 22.

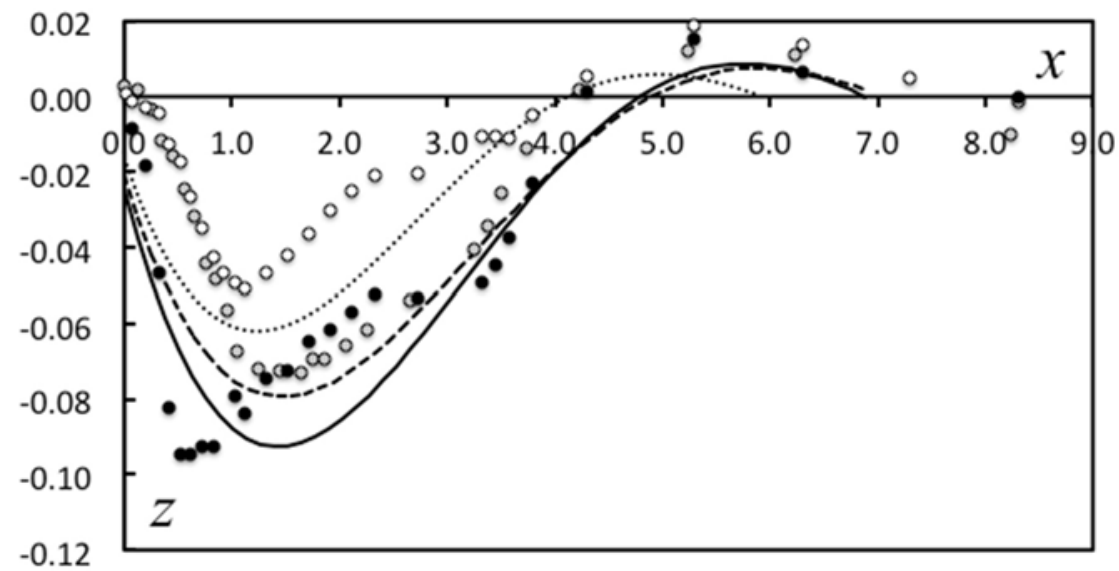

Figure 3: Comparison between observed and calculated values of $z$ (in meters) along the channel centreline. $x$ (in meters) is the distance of the point where $z$ occurs from the upstream end $(x=0)$ of the contraction model. The grey symbols and the dashed curve refer to the run 20 at the time $t=8$ hours, white symbols and dotted curve to the run 21 at the time $t=1$ hour, and black symbols and full curve to the run 22 at the time $t=21$ hours. 


\section{CONCLUSIONS}

Laboratory experiments on spatial and temporal variations of the bed morphology in and around river contractions were carried out at University of Basilicata, Italy. Typically, runs lasted some days to achieve well-developed bed forms, but runs of short duration were also performed to acquire reliable data at the earlier stages of the bed forms development.

Experimental observations revealed that the magnitude of the scour hole would increase with increasing contraction length, and this aspect has not attracted much attention until now. In general, a single thalweg line develops along the channel axis, and it may extend downstream much farther than the contracted region.

Straightforward equations to predict the temporal development of the longitudinal thalweg profile were suggested in terms of the governing parameters. The main dimensionless parameters controlling the maximum relative thalweg depth are in order of importance: the contraction ratio $(\beta)$, the relative length of the contracted reach $\left(l / h_{o}\right)$, the approach densimetric Froude number $\left(F_{d}\right)$, the dimensionless time $(T)$, and the relative submergence $\left(h_{o} / d_{50}\right)$. The relative length of the thalweg profile is mainly dependent on $l / h_{o}$ and $F_{d}$. The ranges of validity for the proposed equations (i.e. eqns (5) and (6)) are $18.81 \leq h_{0} / d_{50} \leq 88.65$, $4.94 \leq l / h_{o} \leq 30.00,0.70 \leq \beta \leq 0.90,1.08 \leq F_{d} \leq 2.44$, and $1.0 \cdot 10^{3} \leq T \leq 2.1 \cdot 10^{6}$. These ranges seem all to get wider when considering literature data.

Further research studies might concern the applicability of the proposed time-dependent relationships under unsteady flow regimes, and the investigation of live-bed conditions.

\section{REFERENCES}

[1] Straub, L.G., Effect of channel-contraction works upon regime of movable bedstreams. Eos, Transactions, American Geophysical Union, 15(2), pp. 454-463, 1934.

[2] Gill, M.A., Bed erosion in rectangular long contraction. Journal of the Hydraulics Division, 107(3), pp. 273-284, 1981.

[3] Dey, S. \& Raikar, R.V., Scour in long contractions. Journal of Hydraulic Engineering, 131(12), pp. 1036-1049, 2005.

[4] Laursen, E.M., Scour at bridge crossings. Journal of the Hydraulics Division, 86(2), pp. 39-54, 1960.

[5] Komura, S., Equilibrium depth of scour in long constrictions. Journal of the Hydraulics Division, 92(5), pp. 17-37, 1966.

[6] Lim, S.-Y., Clear water scour in long contractions. Proceedings of the Institution of Civil Engineers - Water, Maritime and Energy, 101(2), pp. 93-98, 1993.

[7] Lim, S.-Y. \& Cheng, N.-S., Scouring in long contractions. Journal of Irrigation and Drainage Engineering, 124(5), pp. 258-261, 1998.

[8] Dey, S. \& Raikar, R.V., Live-bed scour in long contractions. International Journal of Sediment Research, 21(2), pp. 166-170, 2006.

[9] Brandimarte, L., D’Odorico, P. \& Montanari, A., A probabilistic approach to the analysis of contraction scour. Journal of Hydraulic Research, 44(5), pp. 654-662, 2006.

[10] Benedict, S.T., Clear-water abutment and contraction scour in the coastal plain and Piedmont provinces of South Carolina, 1996-1999. U.S. Geological Survey, WaterResources Investigations Report 03-4064, Columbia, South Carolina, 2016.

[11] Mueller, D.S. \& Wagner, C.R., Field observations and evaluations of streambed scour at bridges. U.S. Geological Survey, Water Resources Divisions Report No FHWARD-03-052, Louisville, Kentucky, 2005.

[12] Hong, S.H. \& Abid, I., Physical model study of bridge contraction scour. KSCE Journal of Civil Engineering, 20(6), pp. 2578-2585, 2016. 
[13] Oliveto, G. \& Marino, M.C., Spatial and temporal variations in bed morphology at river contractions. Proceedings of the International Conference on Fluvial Hydraulics (River Flow 2014), pp. 1469-1474, 2014.

[14] Oliveto, G. \& Marino, M.C., Experimental and numerical investigation of the bed morphology evolution in river contractions. Proceedings of the 36th IAHR World Congress, pp. 1697-1703, 2015.

[15] Oliveto, G. \& Marino, M.C., Bed morphology changes at river contractions. Proceedings of the 8th International Conference on Scour and Erosion, pp. 855-860, 2016.

[16] Graf, W.H. \& Altinakar, M.S., Fluvial Hydraulics - Flow and Transport Processes in Channels of Simple Geometry, John Wiley: Chichester, pp. 10-12, 1998.

[17] Oliveto, G. \& Hager, W.H., Temporal evolution of clear-water pier and abutment scour. Journal of Hydraulic Engineering, 128(9), pp. 811-820, 2002. 